\title{
Los recursos patrimoniales en el turismo actual. El caso del centro histórico de Yecla (Murcia)
}

\author{
ALICIA SORIANO HERNÁNDEZ \\ Universidad de Murcia
}

Recibido: 12-07-2019

Aprobado: 10-10-2019

RESUMEN

La convivencia entre el pasado artístico y cultural de la ciudad de Yecla (Murcia) con los usos actuales de sus elementos patrimoniales constituye el objetivo fundamental de este trabajo. El llamado turismo cultural, en todas sus modalidades, se ha convertido en un recurso económico fundamental para las administraciones locales, por ello proponemos una ruta turística basada en el conocimiento del origen y evolución de la historia y el arte de la ciudad mediante el uso de los recursos patrimoniales que conserva, dotándolos de un discurso ameno pero basado en el rigor de las investigaciones realizadas. Esta ruta se incorporará a la oferta cultural de Yecla aportando respuestas a las necesidades de los diferentes usuarios turísticos locales y foráneos, e introduce el contexto urbanístico como elemento vertebrador. En definitiva, proporcionar un instrumento que además de potenciar el valor de importantes bienes ya reconocidos del patrimonio yeclano permita dar a conocer nuevos elementos de gran valor hasta ahora olvidados y que se encuentran en un lamentable estado de conservación.

PALABRASCLAVE:Ciudad/Patrimonio cultural/TurismoCultural/Arte/Yecla.

\section{ABSTRAC}

The coexistence between artistic and cultural past of the city of Yecla (Murcia) with the contemporary usage of its patrimonial elemets is the fundamental objetive of this work. The so called cultural tourism, in all its forms, has now become a funamental economic resource for local administration. For that reason we suggest a touristic route based on the knowledge of the origin and evolution of the history and art of the city througt the use of the patrimonial resources that the city holds, ia a pleasant way but still based on the precision of the investigations done.

This route will be incorporated to the cultural offer of Yecla adding offer to the demands of the diferent local and foreing touristic targets. It also introduces the urban context as main backbone. Finally, this route will provide a tool that will allow to know new elements of the great value so far forgotten and left in an unfortunate preservation condition on top of enhancing the value of important properties already well recognised in the heritage of Yecla. KEY WORDS: City / Cultural Heritage / Cultural Tourism / Art / Yecla. 
La lectura del patrimonio cultural como fuente de riqueza abre nuevas vías de acción para caminar hacia un desarrollo turístico sostenible, basado en un uso responsable del mismo como garantía de conservación. El patrimonio territorial, lejos de bloquear el desarrollo económico y social, es un poderoso aliado y genera nuevas expectativas económicas y sociales, especialmente en el sector turístico ${ }^{l}$.

Yecla es una ciudad de 34.234 (2018) habitantes, situada en el altiplano murciano, que desde que tenemos noticias de su fundación hasta el siglo XX fue un importante enclave fronterizo entre varios reinos de la Península. Sin embargo diversas circunstancias históricas la abocaron, hasta hace algo menos de una década, al aislamiento,especialmente a través de las rutas con las zonas más turísticas de la Región de Murcia, esto es la costa y la capital, así como del centro Peninsular.

Su Casco Histórico es el centro cultural y patrimonial de la ciudad, especialmente marcado por su configuración y crecimiento durante la Edad Moderna, de manera que el paisaje urbano de Yecla está constituido por edificios construidos entre los últimos años del siglo XV que comparten espacio con diferentes intervenciones culturales del siglo XXI. A la vista de los recursos patrimoniales, su estado, uso y significación urbana y de mi experiencia laboral como becaria del Ayuntamiento de Yecla en el ámbito de museos y yacimientos arqueológicos, y en el ámbito de turismo por mi titulación de guía oficial, fui consciente de la necesidad de dar respuesta a la demanda planteada por los usuarios del "turismo cultural", y las necesidades específicas de los diferentes grupos que lo integran.

Planteamos pues, una serie de cuestiones de partida: ¿es posible aunar a la vez que comprender los diferentes elementos patrimoniales? ¿Se puede establecer un discurso divulgativo y didáctico para la compresión de estos elementos sin perder su importancia como documento y elemento histórico? ¿Pueden constituirse en recursos importantes para el denominado turismo cultural? ¿Podrían estos bienes patrimoniales establecer relaciones de identidad con la población actual de la ciudad y, por lo

\footnotetext{
1 M. Á. TROTIÑO VINUESA y L. TROTIÑO TORRALVA, «Patrimonio y turismo: reflexión teórico-conceptual y una propuesta metodológica integradora aplicada al municipio de Carmona (Sevilla, España)», Scripta Nova, vol. XX, núm.543, 2016, p.15.
} 
tanto, de respeto y usos adecuados del patrimonio? ¿Pueden dichos recursos turísticos y patrimoniales convivir con la ciudad actual?

Como respuesta ha surgido el objetivo fundamental de este estudio ya que se pretende mostrar dónde y cómo se construye el nuevo centro cívico de la ciudad de Yecla, y cómo se desarrolla la arquitectura y las artes que conforman los elementos patrimoniales conservados, los cuales han podido adaptarse, no sin dificultades e incluso actuaciones poco afortunadas, a demandas polivalentes de la ciudadanía, a la vez que son generadores de la imagen, interna y externa, de la ciudad.

Este artículo se enmarca dentro de un proyecto de investigación competitivo a través de mi tesis doctoral, cuyo objetivo fundamental es la localización, catalogación y estudio pormenorizado sobre el impacto del patrimonio cultural en el Altiplano de la Región de Murcia, sus modelos de difusión y enseñanza a los diferentes perfiles de público.

Yecla, como otras ciudades de la Región de Murcia, fue conformada según su estructura actual bajo los cánones de la época Renacentista. Un gran número de los elementos del actual centro histórico fueron construidos desde finales del siglo $\mathrm{XV}$, sometidos cinco siglos más tarde a reformas urbanísticas que marcan los rasgos más importantes de su entorno. Entre los que destaca el principal eje vertebrador de la ciudad — conocido actualmente como la Calle de San Francisco-, cuyas construcciones o reformas se llevaron a cabo fundamentalmente con los cánones clásicos. Siguiendo la proporción y el orden característico del leguaje de la Edad Moderna y de las corrientes culturales del momento, que han llegado hasta laactualidad.

Nuestra propuesta parte de la constatación de que a pesar de la importancia en la morfología, monumentalidad y significado histórico para la ciudad de su crecimiento como villa renacentista, son muchos los vecinos que en la actualidad desconocen las características básicas de sus elementos históricos lo que repercute en la escasa identidad que demuestran la población local y visitante. Atendiendo a que "... el patrimonio cultural de un pueblo comprende las obras de sus artistas, arquitectos, músicos, escritores y sabios, así como las creaciones anónimas, surgidas del alma popular, y el conjunto 
de valores que dan sentido a la vida, es decir, las obras materiales y no materiales que expresan la creatividad de ese pueblo, la lengua, los ritos, las creencias, los lugares ymonumentos históricos, la literatura, las obras de arte y los archivos y bibliotecas" ${ }^{2}$.

Para poder llevar a cabo este estudio, debemos conocer algunos conceptos o definiciones relativos al patrimonio, la cultura y la situación de los propios bienes patrimoniales. En el año 1982, se celebró en Méjico la Conferencia Mundial de la UNESCO, donde se estableció una definición para el concepto de patrimonio cultural, entendiéndolo como " patrimonio cultural representa lo que tenemos derecho a heredar de nuestros predecesores y supone la obligación de conservarlo a su vez para las generaciones futuras"3. Teniendo en cuenta la Carta de Burra, donde ICOMOS Australia definía en 1999 el Sitio como "Lugar, área, terreno, paisaje, edificio u otras obras, y puede incluir componentes, contenidos, espacios y visuales" además, "que significa valor estético, histórico, cientifico, socialo espiritual para las generaciones pasada, presente y futura"(Carta Burra, Artículo 1 y 1; 1.2). Y que posteriormente, el 22 de octubre de 2005 en Xi'an, se siguió acotando la definición de Sitio o Área Patrimonial, concretamente en el documento conocido como Declaración sobre la conservación del entorno de las estructuras, sitios y áreas patrimoniales. Así, para entender estos lugares como patrimoniales deberemos comprender que: "Las estructuras, los sitios o las áreas patrimoniales de diferentes escalas, inclusive los edificios o espacios aislados, ciudades históricas o paisajes urbanos, rurales o maritimos, los itinerarios culturales o los sitios arqueológicos, reciben su significado y su carácter distintivo de la percepción de sus valores sociales, espirituales, históricos, artísticos, estéticos, naturales, científicos o de otra naturaleza cultural. E, igualmente, de sus relaciones significativas con su medio cultural fisico, visualy espiritual. Estas relaciones pueden ser el resultado de un acto creativo, consciente y planificado, de una creencia espiritual, de sucesos históricos, del uso, o de un proceso acumulativos orgánico, surgido a través de las tradiciones culturales a lo largo deltiempo"4.

Y es por esto que "La incorporación del patrimonio a la economía y al turismo de masas, ya sea de forma directa o indirecta, exige coordinación y complementariedad entre

\footnotetext{
2 M.P.GARCÍA CUETOS, El patrimonio cultural: conceptos básicos, Prensas Universitarias de Zaragoza, Zaragoza, 2011,p.13.

3 https://unesdoc.unesco.org/ark:/48223/pf0000052505_spa

4 https://www.icomos.org/xian2005/xian-declaration-sp.pdf
} 
estrategias territoriales, turísticas y culturales. Los cambios en las demandasyen las prácticas turísticas, relacionadas con el uso de las nuevas tecnologías (GPS, realidad aumentada, etc.), requieren que los responsables de la gestión turística apuesten, de forma decidida, por la diversificación geográfica dela ofertaturístico-patrimonial, sies querealmente quieren posicionarse en el llamado "turismo cultural" y cualificar los destinos patrimoniales. Solo así, el patrimonioyel territoriofuncionarán como activos desde la perspectiva delocioy el turismo y, en este mismo sentido, será posible avanzar hacia una alianza estratégica entre turismo y patrimonio, acorde con las características, necesidades y opciones de los diversos lugares del planetay, en suma, integrar el turismo en los programas de desarrolloterritorial" 5 .

Si se aplicasen realmente estos preceptos debería considerarse fundamental el conocimiento, inventario y catalogación de los Bienes, ya que la labor científica es la base de la conservación y a partir de ella podremos interpretar y valorar nuestro patrimonio. Para ello buscaremos referencias en los diferentes planes nacionales de patrimonio cultural $^{6}$, ya que son los instrumentos de gestión del patrimonio, compartidos por las administraciones y con participación de otras entidades públicas o privadas. Y cuyo objetivo es el desarrollo de criterios y métodos comunes, así como unaprogramación coordinada de actividades en función de las necesidades del patrimonio; y por último, la difusión. Precisamente, creando diferentes estrategias dentro de la difusión se pretende acercar el patrimonio, hacer que los elementos patrimoniales no caigan en el olvido o desinterés y sacar a los usuarios de la visión implantada durante años, de dejar el patrimonio solo para los expertos -La idea inicial de patrimonio es, en gran medida, una construcción de las élites sociales, tal como evidencia que, hasta bien avanzado el siglo XX, se vinculase con una visión histórico-artística reduccionista de antigüedades y monumentos y que haya sido largo el camino a recorrer para transitar del monumento al

5 M. Á. TROTIÑO VINUESA y L. TROTIÑO TORRALVA (2016), Op. cit. 8.

6 Los planes nacionales nacieron en la segunda mitad de la década de 1980, una vez que las competencias sobre patrimonio habían sido transferidas a las Comunidades Autónomas y existía una nueva Ley de Patrimonio Histórico -Ley 16/1985, de 25 de junio, del Patrimonio Histórico Español, y Ley 3/1992, de 30 de julio, de Patrimonio de la Comunidad Autónoma de la Región de Murcia-.

Los actuales planes nacionales pueden ser clasificados en tres categorías diferentes. En primer lugar se encuentran los primeros planes elaborados, que tratan sobre los conjuntos patrimoniales clásicos: Catedrales, Monasterios, Arquitectura Defensiva, Patrimonio Industrial. Se elaboraron entre 1987 y 2006. A partir del año 2006 se incorporan nuevos tipos de patrimonio: Paisajes Culturales, Patrimonio Subacuático, Patrimonio Inmaterial, Arquitectura Tradicional, Arquitectura del Siglo XX, Patrimonio Fotográfico. Finalmente, a partir de 2010 se desarrollan también nuevos planes de carácter transversal, dirigidos no a un conjunto de bienes culturales, sino a la forma de conocerlos, conservarlos y difundirlos: Conservación Preventiva, Investigación en Conservación, Educación y Patrimonio, Emergencias y Gestión de Riesgos en Patrimonio. http://www.culturaydeporte.gob.es/planes-nacionales/planes-nacionales.html 
territorio como patrimonio. Una lectura territorial integrada del patrimonio, natural, cultural y paisajístico, será la que realmente pueda permitir que este tenga un papel destacado en la construcción del futuro, un futuro respetuoso con la diversidad natural y cultural del planeta, superando la tradicional disociación entre Naturaleza y Sociedad - y que así sea conocido por un mayor número de personas. Consiguiendo que cada vez el turismo cultural tenga un mayor auge y sea atractivo para los diferentes colectivos, con esto me refiero a llevar prácticas de difusión asociadas a las necesidades específicas de cada uno - como podrían ser niños, familias, personas con diferentes discapacidades, grupos de expertos...- - y adaptadas al uso de las nuevas tecnologías en el caso en el que fueran necesarias.

Estos recursos patrimoniales de Yecla (Murcia) que los encontramos ya en algunas descripciones producto de la sensibilidad de José Martínez Ruiz “Azorín”, en su obra La Voluntad ya aparecen alusiones al patrimonio de la ciudad — dato muy interesante, ya que alguno de los elementos que describe han desaparecido_- "En primer término destacan los dorados muros de la iglesia Vieja, con su fornida torre; más bajola iglesia Nueva; más bajo lindando con la huerta, el largo edificio de las Escuelas Pías, salpicado con los diminutos puntos blancos de sus balcones. Y esparcidos por la ciudad entera, viejos templos, ermitas, oratorios, capillas (...)"”.

Actualmente, el Ayuntamiento de la ciudad de Yecla — junto a la Oficina de Turismo, el Museo Arqueológico Municipal y empresas de carácter privado- ofrece una serie de visitas turísticas guiadas para poner en valor parte del patrimonio de la ciudad. Entre la que incluimos las que se realizan a elementos situados fuera del casco histórico, pero con un valor patrimonial mundial como son las pinturas rupestres y campos de cazoletas (petroglifos) ubicados en el Monte Arabí, destacando los abrigos de Cantos de Visera I, Cantos de Visera II y el Abrigo del Mediodía,declarados Patrimonio de la Humanidad por la UNESCO en el año 1998.

A las visitas del ámbito arqueológico, hay que añadir las nuevas rutas compuestas por paseos por el casco histórico, que nos permitente acercarnos al patrimonio local, junto con los elementos turismo más contemporáneos en la ciudad que son el 
enoturísmo y el oleoturísmo - hay que resaltar la tradición vitivinícola y aceitunera de la localidad, así como la producción de grandes vinos y aceites, premiados en diferentes ferias - Sería muy interesante poder realizar un estudio, sobre todo, en el ámbito del enoturismo para poder insertar esta ruta vinícola en el ámbito de los Itinerarios Culturales del Consejo de Europa ${ }^{9}$. Dentro de estos itinerarios existe Iter Vitis: los caminos de la viña en Europa, su originalidad se centra en la importancia que tiene el paisaje vinícola como elemento cultural integrador en la identidad europea. Con toda su diversidad geográfica y cultural, la vid, y por supuesto el vino, son un patrimonio vivo, no solo por su antigüedad, sino sobre todo por el tipo de actividad económica que generan y por su impacto social ${ }^{10}$. Sumándose a estas propuestas, existen también las visitas y actividades que el Museo Arqueológico Municipal "Cayetano de Mergelina” de Yecla ofrece a turistas y visitantes, de sus colecciones y yacimientos arqueológicos.

Una vez conocida la oferta turística - en cuanto a la difusión del patrimonio cultural - en la ciudad, vamos a centrar nuestra propuesta en el desarrollo de una ruta por el centro histórico de la ciudad de Yecla, utilizando durante todo el recorrido elementos patrimoniales que han sido declarados BIC (Bien de Interés Cultural). El orden establecido para el desarrollo de la ruta, será el cronológico — en la medida de lo que nos permiten los diferentes bienes patrimoniales conservados - para conocer el devenir histórico de la villa y los elementos artísticos y culturales que lo conforman. Dando así a conocer el centro histórico de la cuidad, con el fin de crear un entorno adecuado para el turismo cultural en beneficio de la ciudad en general. Enfocado tanto al visitante local como al foráneo y en el que los recursos artísticos utilizados, lleven a valorar y crear conciencia sobre el patrimonio conservado. Para la elaboración del recorrido se tomará como referencia, como ya he expuesto, el casco histórico de la ciudad y las calles anejas, ya que es el lugar donde se encuentran los recursos de valor patrimonial.

\footnotetext{
9 La iniciativa de los Itinerarios Culturales del Consejo de Europa pretende crear un vínculo entre los ciudadanos de Europa y el patrimonio cultural. Son caminos entre sitios de particular interés, que en ocasiones son vías históricas, pero no solo se trata de rutas turísticas: son un patrimonio vivo, que se basa en el enriquecimiento mutuo del intercambio y facilita la conciencia de una identidad europea común. Cada Itinerario Cultural fomenta la participación ciudadana en un patrimonio cultural democráticamente definido, que no es tan solo interesante por su belleza y su antigüedad, sino sobre todo por su valor inmaterial fundamental.

$10 \mathrm{http} / / /$ www.culturaydeporte.gob.es/cultura/areas/patrimonio/mc/patrimonio-consejo-europa/itinerarios/presentacion/iter-vitis.html
} 

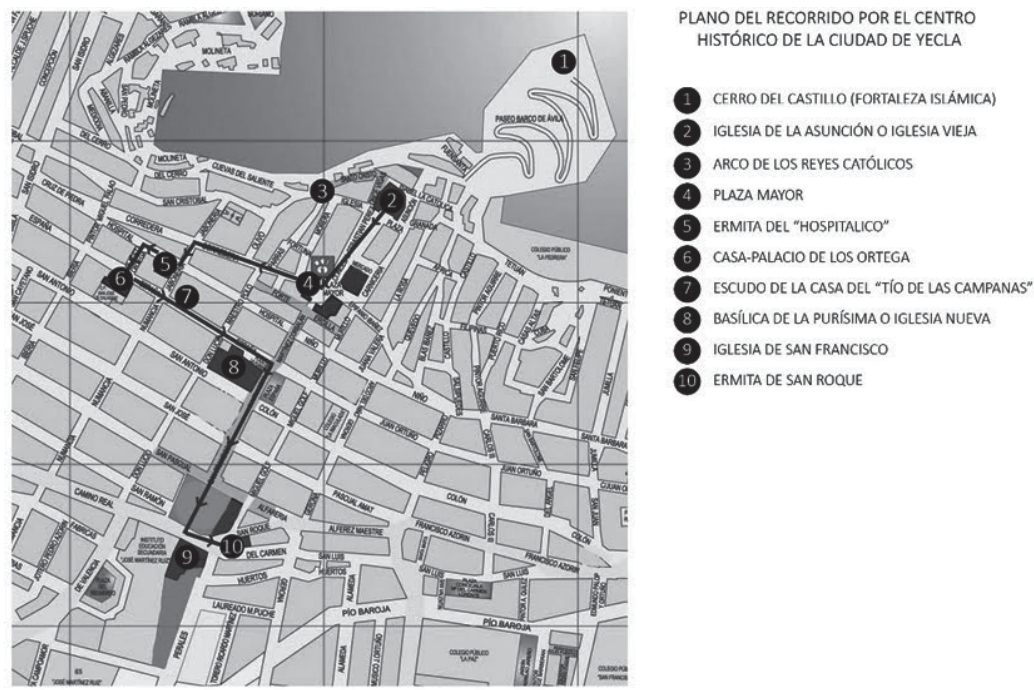

Fig. 1. Plano de Yecla, cedido por la Oficina de Turismo del Excelentísimo Ayuntamiento de Yecla. Infografía Nazaret Soriano Hernández. 2019.

El circuito, está marcado por dos puntos fundamentales: en la zona alta, la Iglesia de la Asunción, y en la zona baja, la Iglesia de San Francisco. Dentro del recorrido contamos con edificios de diferente naturaleza, por un lado encontramos los de carácter religioso: Iglesia de la Asunción o "Iglesia Vieja”, Ermita del Santo Hospital, Basílica de la Purísima Concepción, Iglesia de San Francisco y Ermita de San Roque; y por otro lado, los edificios de carácter civil: Ayuntamiento, Pósito, Casa de los Alarcos, Casa-Palacio de los Ortega, así como los escudos pertenecientes a las antiguas casas nobles (Fig. 1).

El desarrollo actual del centro histórico, es inseparable de la impronta islámica ya que es en este momento cuando se crearán las bases de la ciudad actual — pero no en su ubicación original-, el asentamiento durante este momento — segunda mitad del siglo XI- estaba emplazado en el conocido Cerro del Castillo, en la zona alta se encontraba el hisn o fortaleza y la madina o ciudad se desarrollaba en la cara sur del cerro. Las diferentes excavaciones arqueológicas nos hablan de que conforme fueron haciéndose más fuertes las invasiones cristianas durante el siglo XIII, las instalaciones de este emplazamiento se fueron abandonando. 
"El Hisn Yakka debió ser conquistado hacia el año 1240 por las huestes de Jaime I de Aragón, tras la toma de Villena, y entregado a la Corona de Castilla por el Tratado de Almizra de 1244. El Pacto de Alcaraz de 1243, garantizaba a la población mudéjar, a cambio del pago de rentas, el mantenimiento de su orden social, económico y religioso. El incumplimiento sistemático de éste pacto, y la expropiación de tierras de propietarios mudéjares por parte de los pobladores cristianos, desembocó en la revuelta mudéjar de 12641266. Tras ser sofocadas la revuelta, el reino de Murcia pierde su condición de protectorado de la corona de Castilla, y el pacto de Alcaraz deja de tener vigencia. La posterior represión produjo un fuerte movimiento migratorio y un intenso despoblamiento, dando como consecuencia un cambio en la economía. La pérdida de mano de obra agrícola mudéjar provocó una reorientación hacia la actividad ganadera. Para el caso de Yecla este cambio de orientación económica, justificaría la existencia de cuatro dehesas concejiles y la apertura de la ruta ganadera trashumante de la Cañada Real de los Serranos. A partir del siglo XIV Yecla quedaría en una situación de frontera entre los reinos de Castilla y Aragón. La creación de la aduana y el puerto seco supuso un importante atractivo económico que contribuyó de manera decisiva a la repoblación de estas tierras a partir de la segunda mitad del siglo XIV"'11.

Durante el siglo XV, el nuevo desarrollo de la localidad vendrá fomentado, entre otros factores, por el favor de la Corona hacía la ciudad de Yecla, debido al apoyo que la ciudad le brindó a la Reina Isabel durante la guerra con Portugal por el trono español ${ }^{12}$. Se sabe que el 2 de septiembre de 1476, la reina Isabel la Católica confirmó los privilegios de Yecla, por medio de las promesas que hizo en su nombre Pedro Fajardo, adelantado de Murcia. También en la misma fecha, autorizó a la villa a tener un mercado los martes y prometió no dejar fuera de la Corona Real a Yecla'13; y en el año 1484 los Reyes Católicos ratificaron los privilegios de la Ciudad.

Además, los diferentes documentos y la tradición oral, hablan de una estancia de los Reyes en la Ciudad. Los estudios realizados, confirman que la visita de los monarcas a Yecla tuvo lugar en 1488. Fue en el momento en que regresaban

\footnotetext{
11 https://museoarqueologicodeyecla.org/edad-media/

12 Con la muerte de Enrique IV en 1474, Don Diego López Pacheco, Marqués de Villena - territorio al que pertenecía la villa de Yecla en ese momento-, no aprueba el acceso al trono de Isabel I de Castilla, conocida posteriormente como Isabel "la Católica", ya que bajo su tutela se encontraba la princesa Juana, hija y heredera del difunto rey.

13 Archivo General de Simancas, Reg, Gral. Sello I, 1443,fol. 585; Ibídem, I, 1446, fol. 631.
} 
a Castilla, tras una estancia de la corte en Murcia en su afán de conquistar la ciudad de Granada ${ }^{14}$.

Durante el siglo XVI, período caracterizado por años de tranquilidad, la Ciudad de Yecla se encuentra totalmente integrada en la sociedad y economía española. En su territorio no se asientan grandes terratenientes, esta situación cambiará en el último tercio del siglo, cuando se desarrolla el cultivo de la vid, haciendo que diferentes familias se enriquezcan en poco tiempo, provocando un cambio positivo para la economía de la Ciudad ${ }^{15}$.

Otro elemento generador de desarrollo de la ciudad fue la aduana ${ }^{16}$ de Yecla, llegó a ser la segunda en importancia de España, creando una sería de beneficios muy importantes para el progreso de la ciudad. El auge de la ciudad, propició el desarrollo urbano y el traslado del centro con el habitual descenso hacía el valle una vez que el castillo y las zonas altas habían quedado obsoletas ${ }^{17}$, dando lugar así a la construcción del nuevo Ayuntamiento en 1514, y la creación del nuevo centro cívico, al igual que sucede en otros territorios del Reino. Este nuevo centro, estaba formado por el ayuntamiento, la parroquia, la lonja, la carnicería y los comercios de primera necesidad, junto con otros edificios de carácter privado y el establecimiento de las calles como ejes de conexión entre los diferentes puntos de la Ciudad. Podríamos decir que durante el siglo XVI es cuando la ciudad de Yecla queda estructurada urbanísticamente, manteniendo las características de este momento hasta la actualidad. Con llegada del siglo XVIII, se produjo un momento de desarrollo en la ciudad a nivel urbanístico y social. Urbanís- ticamente la ciudad comienza a proyectarse hacia el norte, siguiendo un trazado orde- nado de calles y plaza. Es en este momento cuando se comienza la construcción de la Basílica de la Purísima y de las casas nobles de la sociedad yeclana (Fig. 2).

14 J. BLÁZQUEZ MIGUEL, Yecla en su Historia. Desde los primeros pobladores hasta la Guerra de la Independencia. Vol. I, Editorial Arcano, Toledo, 1989, p. 59.

15 Proceso que se ha repetido en la actualidad, cabe recordar que la ciudad de Yecla mantenía su economía mayoritariamente por la industria del mueble. La industria del mueble se vio gravemente afectada por la crisis de los últimos años, buscando la solución a los problemas de la ciudad en la industria vitivinícola y el turismo asociado a ella, con el llamado enoturísmo que actualmente está moviendo una gran cantidad de turistas nacionales e internacionales.

16 El objetivo principal de las aduanas era la recaudación de impuestos, dinero que pasaba a lo Corona. Los principales impuestos que allí se cobraban eran los que recaían sobre animales o mercancías. Había un total de 39 aduanas, siendo la de Yecla la segunda después de la de Requena. El mayor número de dinero se recaudaba por los impuestos sobre la lana, ya que pasaba por Yecla, camino de Villena, para que llegara al puerto de Alicante. J. BLÁZQUEZ MIGUEL, (1989): Op.cit.

$17 \quad$ Es el modelo que se repite en toda Europa desde finales del siglo XIV, y que en el territorio sur oriental de la Península hay que esperar a las últimas décadas del siglo XV, Totana, Moratalla, Cehegin, Yecla. 


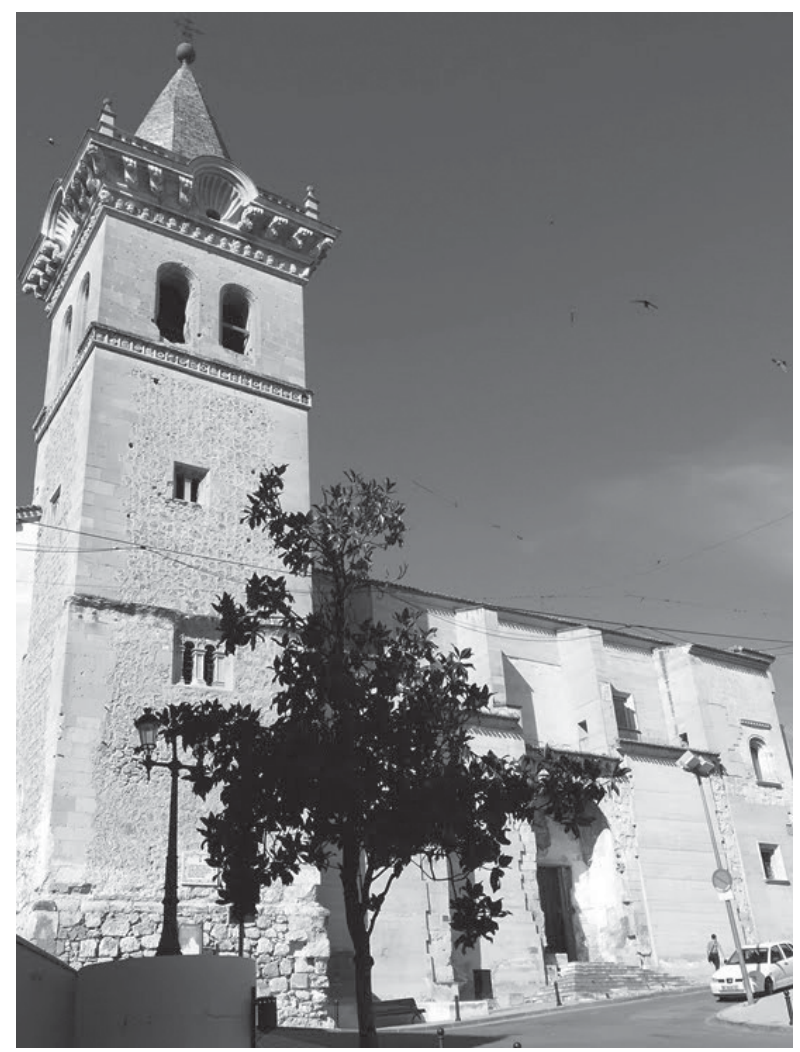

Fig. 2. Alicia Soriano Hernández. Iglesia de la Asunción, 2019, Yecla.

El punto de partida para conocer el valor de los elementos patrimoniales de Yecla será la Iglesia de la Asunción o "Iglesia Vieja”-como popularmente se la conoce en la ciudad desde la construcción de la basílica de la Purísima-. De entre todos los edificios renacentistas que se conservan en Yecla, es el que mayor importancia y trascendencia ha tenido a lo largo del tiempo -actualmente está declarada como Bien de Interés Cultural con categoría de Monumento-. Constituye un ejemplo de los inicios, asimilación y desarrollo de las formas renacentistas en España llamado a convertirse en el eje del nuevo espacio urbano de la ciudad, como resultado del crecimiento de la población durante la Edad Moderna y que será abandonada después de la construcción del nuevo templo de la Purísima y definitivamente tras los graves daños sufridos durante la Guerra Civil — como la perdida de todo el archivo documental por la 
quema de la iglesia, llevando a un vacío de información en todo lo que tiene que ver con la construcción de la misma-.

La Iglesia fue proyectada durante la última década del siglo XV, como una iglesia de nave única con capillas hornacinas entre los contrafuertes. Tipológicamente, se corresponde con las iglesias levantadas al final de la vida de Isabel la Católica, en la última década del siglo XV. De este momento se conserva alguna de las decoraciones del interior del templo, destacan algunos de los arranques de los nervios en las bóvedas de las capillas —en alguna de estas decoraciones aparece el águila, motivo que puede interpretarse como la representación de la Reina Isabel otorgando así el carácter de fundación real a la iglesia-, tondos decorativos en la nave central con elementos relativos a la Pasión de Cristo... En el siglo XVI se realizan una serie de reformas, que modificaran el interior y exterior del templo y su entorno. Las reformas se ejecutaron sobre la torre, la cabecera, el coro, el nuevo acceso que se abre a la iglesia, la sacristía y la única capilla del último cuerpo. Una de las reformas más llamativas será la del nuevo acceso, ya que supone un importante cambio conceptual que refleja el urbanismo de Yecla. La abertura de esta nueva portada hacia el centro urbano situado en la plaza, deja patente una clara relación entre lo civil y lo religioso.

La cronología aproximada para el inicio de la construcción de esta iglesia estaría en torno a 1490, teniendo en cuenta su separación del Marquesado de Villena en 1476 y los privilegios otorgados a la ciudad por Isabel la Católica en 1484. Realizándose la reforma hacia 1530, ya que según la fecha que figura entre el segundo y tercer cuerpo de la escalera de la torre -1541- la torre campanario debió de estar terminada en los años inmediatamente posteriores a 1541, se podría hablar de aproximadamente $1542-45^{18}$. Será la reforma de la torre y, sobre todo, su decoración exterior la que nos de las pautas para entender la organización de la 'nueva' ciudad. Se trata del modelo de torre renacentista, dividida en tres cuerpos y rematada por una aguja. Se accede al interior, por medio de un arco que se abre a un lado de la cabecera y se asciende por una escalera de caracol de piedra sillar. En los cuerpos que forman la torre encontramos unas estancias cuadradas, cubiertas con bóvedas nervadas y donde la decoración conservada se concentra en los arranques de esos nervios — caras, motivos de la Pasión de Cristo, decoración vegetal—.

18 A. SORIANO HERNÁNDEZ, «El programa iconográfico de la Iglesia Vieja», Yakka, Revista de Estudios Yeclanos, AÑO XXI- Número 18, 2009-2010, pp. 27-69. 
Es en el ascenso entre el segundo y tercer cuerpo dónde encontramos uno de los elementos más importantes para el estudio de la iglesia,la fecha de 1541 labrada en la piedra y nos lleva a poder realizar una datación aproximada de todo el conjunto de la Iglesia. Además, aparecen diferentes marcas de cantero en los sillares, algunas de éstas se encuentran también labradas en las piedras que conforman la Catedral de Murcia, lo que nos permiten poner en relación a los maestros que trabajan en la Catedral y en este templo. En la estructura exterior de la torre encontramos lo más interesante de su programa ornamental, el llamado friso de cabezas que decora el cuerpo superior. Se trata de una banda que recorre las cuatro alas de la torre, con treinta y dos cabezas esculpidas en medio relieve, menos cuatro cabezas colocadas en las esquinas y esculpidas en un alto relieve. Estudios anteriores hablan de la representación en los frisos de los estamentos sociales: nobleza, clero y estado llano, y un cuarto friso dedicado al orden militar. Así, como la identificación de tres de las cuatro cabezas de las esquinas con las de un hombre joven, un hombre maduro y un hombre anciano, simbolizando las formas del tiempo en general. Y la cuarta, haciendo alusión a una cabeza de león que personifica la virtud de la prudencia. Es la ordenación de los frisos lo que ocupa mi interés, ya que nos aproxima al paisaje urbano de la Yecla del siglo XVI, en su posición se puede leer la división social de la ciudad. En el friso N, encontramos las caras alusivas a la realeza. Este friso queda en relación directa con el ensanche que se abre para llegar hasta el edificio del Concejo, se estaría afianzado así la unión entre el poder religioso y el civil; Friso NW, representa el clero, está orientado hacía el conocido como Barrio del Peñón, antigua alquería islámica. Quedando así esta zona y su religión vigilada por la Iglesia; Friso NE, en el que se plasma el orden militar, los guerreros, estaría apuntando hacia el lugar en el que se presupone que se encontraba la antigua judería, lanzando un claro mensaje a la población que ocupaba este espacio. Separado hoy en día por el conocido Arco de los Reyes Católicos, atravesándolo los Reyes llegaron al corazón de la villa en 1488. Lo lógico es pensar que se trate de una puerta que separaba la zona judía de la cristiana, y no de un simple arco; Friso S, en el que se representa el pueblo llano. En éste aparecen calaveras, relacionadas directamente con el lugar al que apunta que es el antiguo cementerio de la ciudad.

La Iglesia Vieja fue el principal templo de la ciudad de Yecla hasta el año 1868, aunque será durante la Guerra Civil Española el momento en el que el templo 
pierda toda su monumentalidad y se convierta en el edificio olvidado de hoy. En el año 1961 se realizaron los primeros trabajos de consolidación del edificio, aunque fue a partir de su declaración en 1982 como Monumento Histórico-Artístico y su cesión por el Obispado de Cartagena al Ayuntamiento de Yecla durante un período de noventa y nueve años, con la finalidad de hacerse cargo de la conservación del mismo, cuando se iniciaran los trabajos de rehabilitación en varias fases. La primera: entre 1985 y 1988, mediante unas pautas erróneas que han causado grandes daños al inmueble — inyección de hormigón sobre piedra caliza —; la segunda: 1991-1993, con la adecuación del entorno y creación de un anfiteatro al aire libre sobre el antiguo cementerio $^{19}$. Actualmente, se utiliza el espacio como museo de la Semana Santa sin ningún tipo de criterio expositivo o de conservación. En 2019, seguimos esperando una rehabilitación que le devuelva a la Iglesia y su entorno todo el esplendor y monumentalidad de siglos pasados.

El segundo punto de la visita estaría situado en la Plaza Mayor. Dentro del conjunto encontramos diferentes construcciones del siglo XVI: el ayuntamiento, la casa de los Alarcos y el pósito del pan. El Ayuntamiento, es una obra perteneciente a la primera mitad del siglo XVI, en su construcción se observan algunos de los esquemas que habían sido utilizados por Vandelvira ${ }^{20}$. Al exterior, la fachada contiene un doble arco, sobre los cuales aparecen grandes balcones. Entre estos dos se encuentra el escudo imperial de Carlos V del águila bicéfala — declarado Bien de Interés Cultural—. Otros elementos destacables de la fachada son: el balcón o ventana de ángulo y sobre esta una escultura que representa a Hércules ${ }^{21}$. El interior, fue remodelado en el siglo XIX por el arquitecto Justo Millán. En la remodelación, afortunadamente, se conservó el escudo de Juana I, más conocida como Juana "la loca", situado en la zona alta de la gran escalera que da acceso al primer piso del edificio. Adosada al edifico del ayuntamiento, encontramos la Torre, edificada en 1687 - utilizada como prisión-, de planta cuadrada y cubierta exterior a cuatro aguas. Lo más interesante de la edificación se encuentra sobre el balcón, y es el escudo de la ciudad de Yecla — declarado Bien de Interés Cultural—, es el más antiguo del que se tiene

\footnotetext{
19 F.J. DELICADO MARTÍNEZ, «La Iglesia de la Asunción de Yecla (Murcia)», Yakka, Revista de Estudios Yeclanos, Número 14, 2004, pp. 59-80.

20 Andrés de Vandelvira (1509-1575), uno de los principales arquitectos y canteros español del siglo XVI, sobre todo en la zona de Jaén, sus modelos se difundirán por toda Andalucía llegando hasta la Américavirreinal.

21 F.J.DELICADO MARTÍNEZ, «La plaza mayor de Yecla: arquitectura y urbanismo», Archivo de arte valenciano, $\mathrm{N}^{\mathrm{o}} 70,1991$, pp. 26-29.
} 
constancia y se acompaña de la inscripción: "REINADO CARLOSII YECLA MANDO HACER ESTAS ARMAS SIENDO COMISARIOS D. ANTONIO MUÑOZ VICENTE Y D. JUAN SPUCHE ORTUÑO, REGIDORES. AÑO 1687”. El escudo está compuesto por una torre almenada que se proyecta sobre rocas, combatidas por el mar, con un león encadenado a la puerta del castillo. Rematado por corona marquesal cerrada $^{22}$; La Casa de los Alarcos — actualmente forma parte de las instalaciones del ayuntamiento-, se trata de un edifico del final del Renacimiento, dentro del estilo purista castellano, sin decoración. El paso del tiempo y los diversos usos que se le ha dado, han hecho que su forma original haya ido desapareciendo; El Alhorío pósito del pan, también es una construcción del siglo XVI realizada con la sobriedad que caracteriza a todo el conjunto de la Plaza Mayor.Lo más característico del edificio son sus soportales, presenta una galería abierta que descansa sobre unas pilastras toscanas, realizadas en piedra arenisca-piedra local, conservándose en muy mal estado debido a la erosión ${ }^{23}$. Junto al pósito encontramos la antigua lonja, actualmente, se utiliza como auditorio municipal. Adosada a ella, se localiza la conocida como Torre del Reloj, que formaba parte de la desaparecida Ermita de la Virgen de las Nieves del siglo XVII (Fig. 3).

Continuando el recorrido seguiremos por la Calle de la Corredera, que como en tantos otros lugares, marcará el paseo de la villa desde 1527, posiblemente sea la calle con nombre conservado más antiguo documentado en la ciudad ${ }^{24}$. Girando en la Calle de la Corredera por la Jabonerías ${ }^{25}$ nos encontramos con la Ermita del Santo Hospital, llamada así por formar parte del Conjunto del Hospital de la Caridad e Iglesia-declarado monumento histórico-artístico de carácter nacional desde el año 1982-, referenciado en las "Relaciones Topográficas" de Felipe II en el año $1575^{26}$. En la actualidad, de la primera ermita renacentista solo se conserva en la fachada un arco y una pequeña hornacina en la parte superior de éste. La iglesia actual, bajo la advocación de Nuestra Señora de los Dolores, está construida sobre la ermita del XVI. De planta de cruz latina y con una sola nave, en el interior destaca su decoración propia del barroco

\footnotetext{
2 F.J.DELICADO MARTÍNEZ (1991). Op. cit.

23 F.J. DELICADO MARTÍNEZ, «Arquitectura Renacentista en Yecla (Murcia)». Príncipe de Viana, $\mathrm{N}^{\mathrm{o}}$ 12, 1991, pp. 153-160.

24 M. ORTUÑO PALAO y C. ORTín MARCO, Las calles de Yecla, Ediciones del Azar S.L., Barcelona, 2003, p. 68 .

25 Existente desde 1588. Se le dio ese nombre ya que ahí trabajaban los fabricantes de jabón, en M. ORTUÑO PALAO y C. ORTÍN MARCO (2003): Op. cit. p. 120.

26 J. BLÁZQUE MIGUEL, Yecla en tiempo de Felipe II (1556-1598), Imprenta La Levantina, Yecla, 1981, p.39.
} 


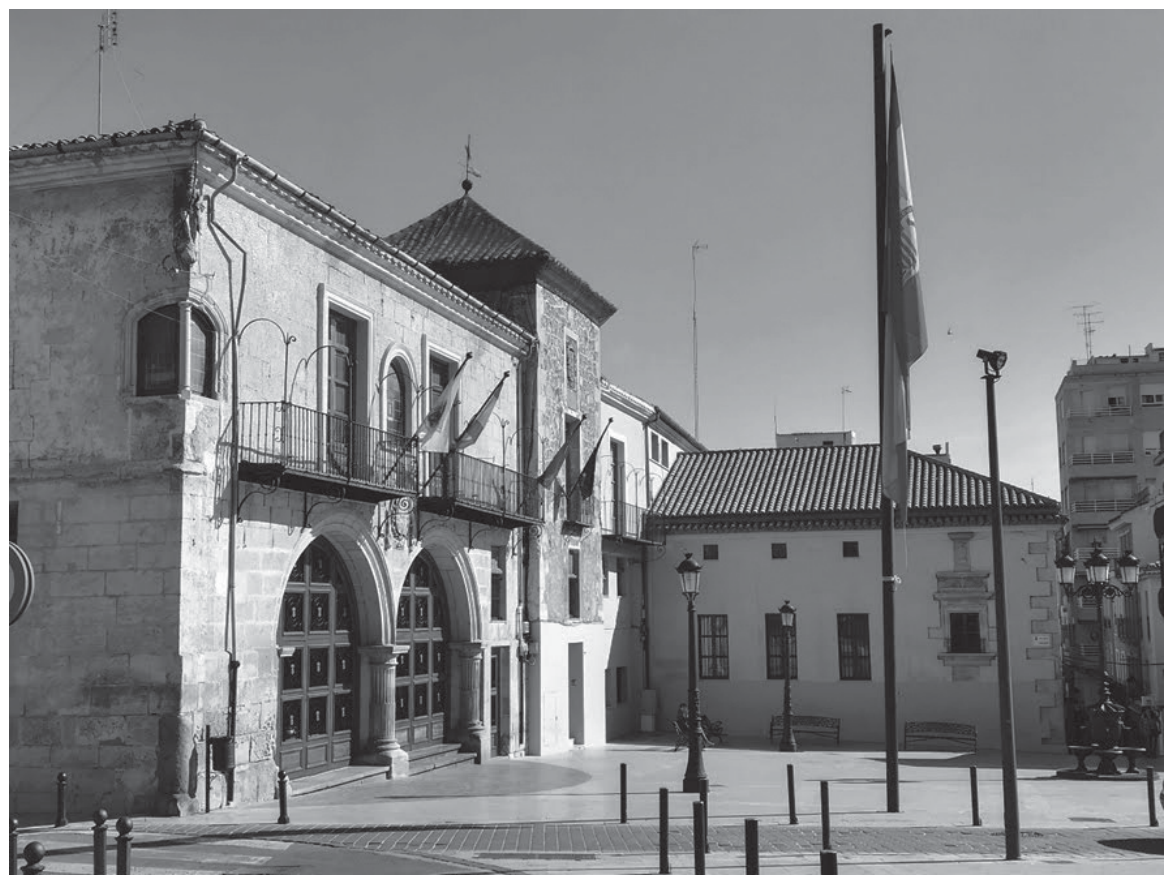

Fig. 3. Alicia Soriano Hernández. Plaza Mayor, 2019, Yecla.

murciano, del patrimonio mueble de la iglesia no se conserva apenas nada, ya que durante la Guerra Civil fue arrasada como la mayoría de iglesias del municipio; al exterior nos encontramos con una fachada neoclásica, donde la fecha de 1846 nos hace saber el año de su construcción. El edificio anexo, conocido popularmente como el hospitalico, tuvo diferentes funciones a lo largo de su historia como Casa de la Misericordia y Junta de Caridad hasta 1900, será sede del sindicato agrícola, archivo notarial y colegio de enseñanza, y entre 1954 y 1979 centro maternal y pediátrico de urgencia ${ }^{27}$. También se utilizó como escuela de música municipal, y actualmente forma parte de las dependencias municipales como lugar cedido para el uso deasociaciones.

Siguiendo el recorrido por la Calle Hospital, conocida así desde 1560 por estar construyéndose la ermita del Hospitalico ${ }^{28}$ llegaremos a la Placeta Ortega, el

$27 \quad$ F.J. DELICADO MARTÍNEZ, «El antiguo Hospital de la Caridad e iglesia aneja de Nuestra Señora de los Dolores, de Yecla (Murcia): Mecenazgo, espacio arquitectónico y patrimonio mueble», Archivo de arte valenciano, $\mathrm{N}^{\circ}$ 92, 2011, pp. 106-142.

28 M. ORTUÑO PALAO y C. ORTÍN MARCO (2003): Op. cit. p. 112. 
nombre viene dado por el apellido del señor que la ejecutó. Ya desde 1746 se la conoce por este nombre, fue José Ortega Ortuño quién en 1773 mandó derribar las casas que había frente a su palacio para darle mayor prestigio ${ }^{29}$. El punto de interés de la plaza es el edifico de la Casa-Palacio de los Ortega, actualmente es el edificio donde se encuentra la Casa Municipal de Cultural, en su interior se encuentra la Biblioteca y el Archivo Municipal, la Fundación Castillo-Puche, el depósito bibliográfico y documental Pablo Corbalán. Así como los espacios expositivos más importantes de la ciudad, el Museo Arqueológico "Cayetano de Mergelina”, el Museo de Réplicas de "El Greco", la Sala-museo del pintor Rico López y la sala de exposiciones municipal. En el exterior del edificio, en la fachada encontramos otro de los bienes culturales de la ciudad, concretamente en la zona alta de la portada se ubica el escudo de la familia. En el interior, se conserva buena parte de la estructura original. En el siglo XIX el palacio fue comprado por la familia Portillo, y remodelado por el arquitecto Justo Millán Espinosa (Fig. 4).

La Casa-Palacio de los Ortega está ubicada en la Calle España, como decía más arriba, durante el siglo XVIII, se dio un momento de desarrollo en la ciudad a nivel urbanístico y será en esta calle donde se encuentran las grandes casas solariegas -por desgracia, muchas de ellas hoy desaparecidas o en un estado deplorable- con sus escudos familiares en las fachadas, como ejemplo de estos escudos de la casa conocida como la del "tío de las campanas"-escudo declarado Bien de Interés Cultural- ubicada en la Calle España n² 24 y datado a principios del siglo XIX ${ }^{30}$. Debemos apuntar, que en la actualidad la casa se encuentra casi en estado de ruina y si no se lleva a cabo una actuación urgente sobre la misma, la consecuencia será una gran pérdida para el patrimonio local. Será esta misma Calle España la que nos lleve hasta una de las construcciones más icónicas del patrimonio yeclano, la Basílica de la Purísima.

La Iglesia Parroquial de la Purísima Concepción o Iglesia Nueva ${ }^{31}$-Bien de Interés Cultural con la categoría de Monumento-, ubicada en el centro del eje vertebrador de la ciudad de Yecla, fue construida por y para el pueblo, y casi cien años se

29 M. ORTUÑO PALAO y C. ORTÍN MARCO (2003): Op. cit. p. 174.

30 F. E. RUIZ IBÁÑEZ, Yecla. Repertorio Heráldico en Repertorio de Heráldica de la Región de Murcia, nº4, Editorial KR, Murcia, 2001, p. 101

$31 \quad$ Nombre que la población le da coloquialmente, al haberse construido cuando todavía estaba en uso la Iglesia de la Asunción o conocida también como Iglesia Vieja. 


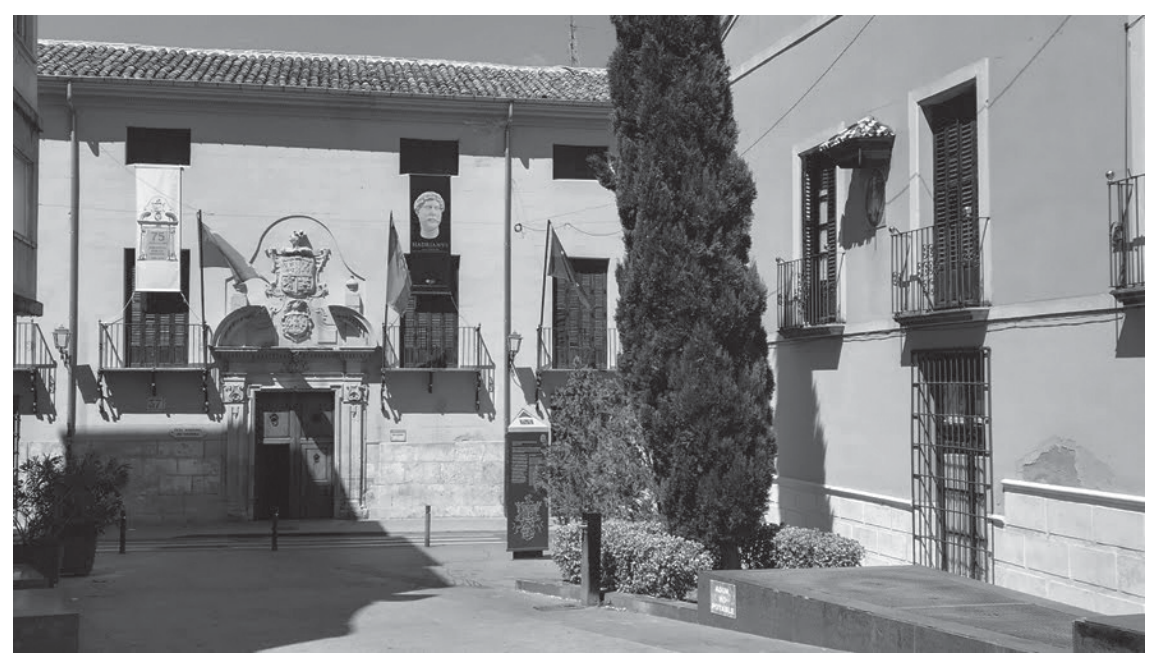

Fig. 4. Alicia Soriano Hernández. Casa-Palacio de los Ortega, 2019, Yecla.

tardaron en finalizarla. Su construcción se llevó a cabo en dos fases, los inicios en el año 1775 por José López, quien realizó los planos; y en una segunda fase, con Jerónimo Ros, que será quién termine la construcción en el año 1868 y también quién se encargue de la cúpula, elemento que actualmente es el símbolo de la ciudad de Yecla. Realizaba dentro del estilo Neoclásico, su exterior está inconcluso. Llama la atención la terminación de la fachada de una forma muy austera - hay que resaltar que el hecho de que fuera financiada por pueblo alargó su ejecución, y también cambió sus dimensiones acortando el transepto de la misma- . El templo se estructura con planta de cruz latina con tres naves, separadas por arcos de medio punto con cúpula semiesférica, decorada con teja vidriada azul y blanca en espiral, sobre el crucero y capillas entre los contrafuertes, entre ellas destaca la Capilla de la Comunión ${ }^{32}$ (Fig. 5).

En el interior, destacan las pinturas de las bóvedas obra del lorquino Manuel Muñoz Barberán, entre los años 1953-1956, y las de la cúpula del artista Rafael Roses de Rivadavia. En la iglesia, actualmente, se conservan dos de las imágenes más importantes de la ciudad - las obras escultóricas originales de la iglesia desaparecieron durante un incendio en el año 1936 33 _. La Virgen de las Angustias (1764) de

\footnotetext{
32 https://www.regmurcia.com/servlet/s.Sl?sit=a,99,c,522,m,1075\&r=CeAP-2362-C_710_DETALLE_CENTRO

33 F. J. DELICADO MARTÍNEZ, «Arquitectura neoclásica en Yecla. La iglesia de la Purísima», Yakka, Revista de Estudios Yeclanos. N ${ }^{\circ} 17,2007-2008$, pp. 29-86.
} 


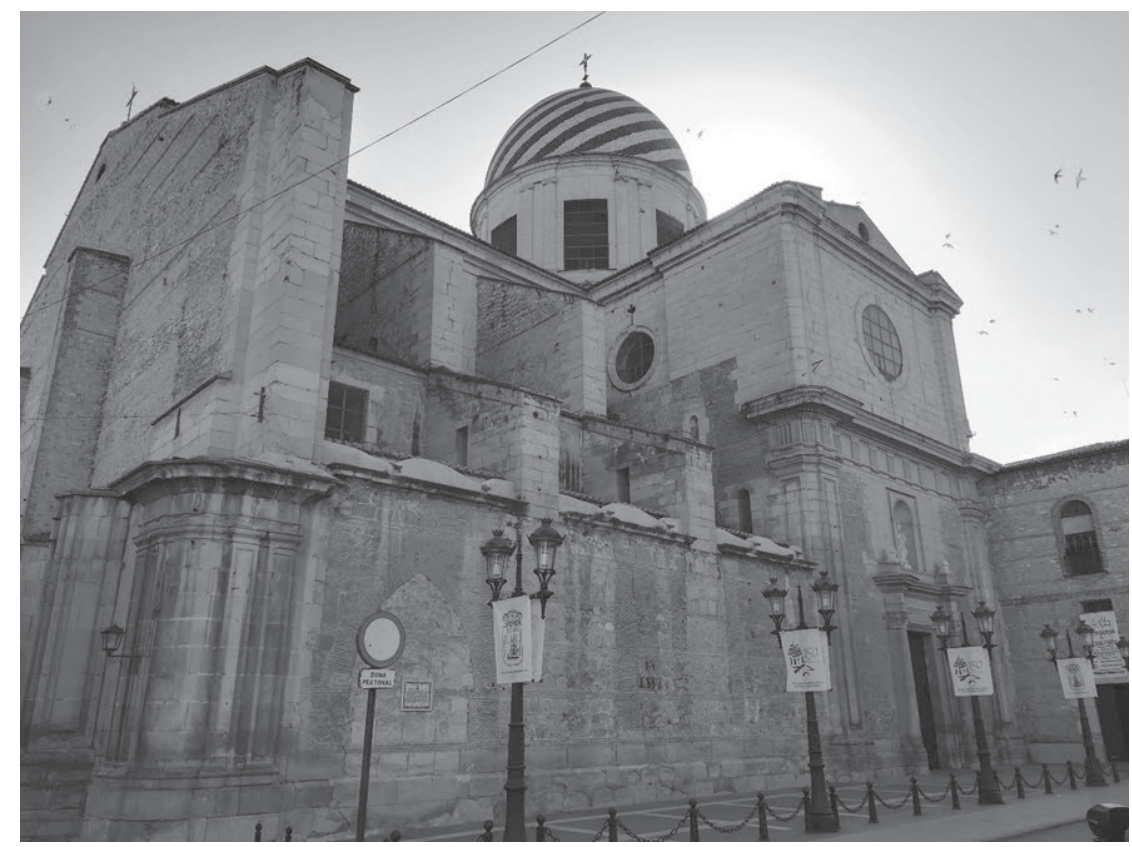

Fig. 5. Alicia Soriano Hernández, Basílica de la Purísima, 2019, Yecla.

Francisco Salzillo — procedente de la Iglesia de San Francisco- y el Cristo a punto de ser enclavado en la Cruz arrodillado sobre el sagrado madero (1800) — procede de la Iglesia de la Asunción— de José Esteve Bonet.

Descendiendo por la Calle de San Francisco nos encontramos con la iglesia del mismo nombre. La iglesia de San Francisco fue construida por los franciscanos a finales del siglo XVI junto con un convento para los monjes, hoy desaparecido ${ }^{34}$. El Convento de San Francisco estaba compuesto por el conjunto conventual, la Iglesia de San Francisco y Capilla de la Orden Tercera o de la Virgen de las Angustias - con declaración de Bien de Interés Cultural- . De la iglesia del siglo XVI solo se conserva la planta en forma de cruz latina, en el año 2014 fue rehabilitada y quedando el espacio reservado para diferentes usos, conciertos, exposiciones... al exterior, lo que más llama la atención es la gran espadaña realizada a principios del siglo XVIII (Fig. 6).

34 Las obras se llevaron a cabo en los años 60 del siglo XX. Antes de desaparecer para construir en su lugar el I.ES. “Azorín”, fue el lugar donde se ubicaban las Escuelas Pías en las que estudió el célebre escritor José Martínez Ruiz “Azorín”. 


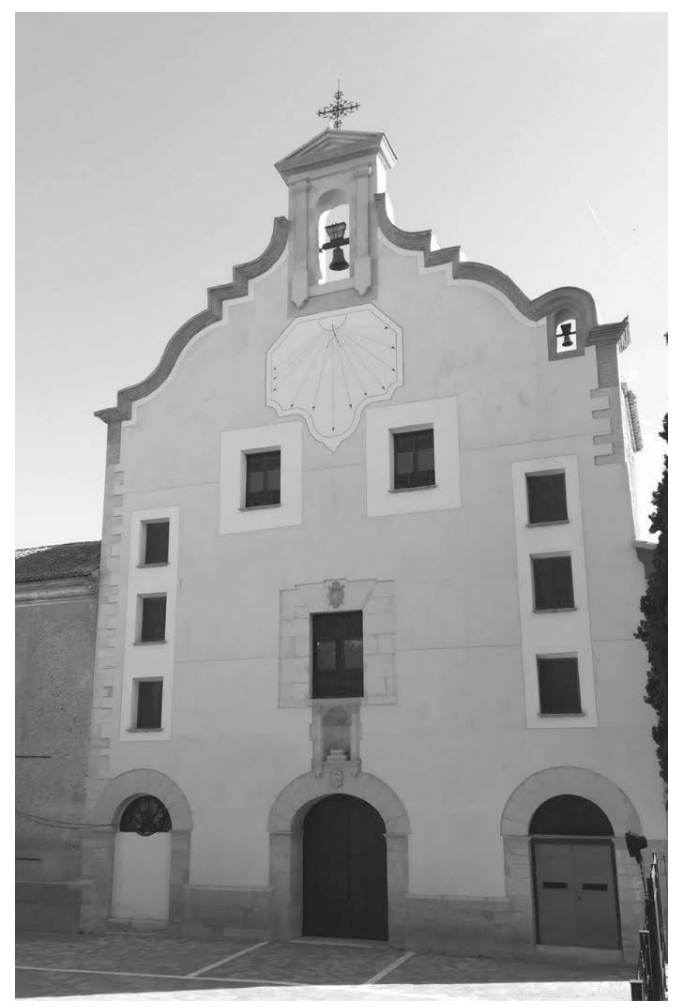

Fig. 6. Alicia Soriano Hernández, Iglesia de San Francisco, 2019, Yecla.

Junto a la iglesia, encontramos la Capilla o Camarín de la Virgen de las Angustias —debido al estado ruinoso del conjunto, se han redactado informes para llevar a cabo su rehabilitación que de momento no se ha realizado, esperamos que un corto periodo de tiempo se realicen y el espacio pueda ser accesible y visitable — de la Orden Tercera Franciscana Seglar, situada a la izquierda de los pies de la iglesia. Construida a principios del siglo XVIII, es una fantástica obra del barroco levantino en el que destaca la utilización, para decorar el camarín, de la azulejería valenciana representando seis de los siete dolores de la Virgen, siendo el último dolor la imagen de la Virgen de las Angustias de Francisco Salzillo ${ }^{35}$.

Para terminar el recorrido cultural por el casco histórico de la ciudad de Yecla, se propone la Ermita de San Roque, ubicada a escasos metros del conjunto de

35 F.J. DELICADO MARTÍNEZ, «El convento de franciscanos de Yecla, una fundación del siglo XVI», Yakka, Revista de Estudios Yeclanos, № 13. Yecla, 2003, pp. 85-114. 
San Francisco - en las zonas denominadas como huertas, pero hoy inmersas en la ciudad por la evolución de la misma_- Para Delicado Martínez "La mudéjar ermita de San Roque de Yecla que hoy contemplamos es un edificio datable estilísticamente en el siglo XVI, en opinión de Elías Tormo, Torres Balbás, Pérez Sánchez, Belda Navarro y Javier Delicado. Recientemente Cristina Gutiérrez-Cortines Corral ha subrayado que "no es fácil de fechar San Roque de Yecla, cuya existencia estaba documentada en el siglo XV, pero en opinión de Pérez Sánchez tal vez fue reformada cuando se aceptó el copatronazgo de San Sebastián y San Roque a comienzos del siglo XVI. La ausencia de decoración mudéjar podría confirmar esta cronología, aunque siempre sobre la base de una techumbre muy simple, adoble vertiente, con las vigas transversales a los arcosyun almizate de escasa entidad "36, confiriéndole esta explicación el carácter de uno de los templos más antiguos de la ciudad junto con la Iglesia de la Asunción. Al interior, lo más interesante es el artesonado de madera en la nave única soportado con arcos de fábrica de medio punto. Al igual que sucede con todos los elementos descritos anteriormente, se trata de un Bien de Interés Cultural.

Presentada la ruta finalizaremos dando respuestas a las preguntas que se planteaban al inicio del estudio. A la pregunta de si es posible aunar y comprender los diferentes elementos patrimoniales de la ciudad podemos contestar afirmativamente, siempre y cuando se utilicen los recursos adecuados y el argumento que les proporcione coherencia. Como en este caso podemos utilizar un orden cronológico o de naturaleza del bien patrimonial, para entender y valorar el pasado del que somos parte.

La respuesta a si se puede establecer un discurso divulgativo y didáctico para la compresión de estos elementos sin perder su importancia como documento y elemento histórico, no es que se pueda es que se debe. Nosotros como divulgadores y difusores del patrimonio tenemos la obligación de ofrecer discursos adecuados al público existente, formándonos para una transmisión idónea de los diferentes sucesos histórico-artísticos y culturales presentes en los bienes patrimoniales. Para ofrecer un mejor valor de difusión deberemos buscar recursos en otras disciplinas como la pedagogía o la didáctica, que nos harán llegar de manera más fácil a diferentes necesidades de cada colectivo.

\footnotetext{
36 F. J. DELICADO MARTÍNEZ, «Una aproximación al mudéjar del siglo XVI murciano: la ermita de San Roque y San Sebastián de Yecla», Yakka, Revista de Estudios Yeclanos, № 5, 1994, pp. 91-106.
} 
Responder a la pregunta de que si los diferentes elementos patrimoniales del casco histórico de la ciudad de Yecla pueden constituirse como elementos para el denominado turismo cultural, es muy fácil. Todos los elementos seleccionados para esta ruta tienen la declaración de Bien de Interés Cultural, atendiendo a la definición del término que aparece en la Ley 16/1985, de 25 de junio, del Patrimonio Histórico Español -la figura será asumida a posteriori por las leyes de las diferentes comunidades autónomascomo "cualquier inmueble y objeto mueble de interés artístico, histórico, paleontológico, arqueológico, etnográfico, científico o técnico, que haya sido declarado como tal por la administración competente. Y el patrimonio documental y bibliográfico, los yacimientos y zonas arqueológicas, así como los sitios naturales, jardines y parques, que tengan valor artístico, histórico o antropológico, así como usos y costumbres tradicionales". Es por esto que creemos que la ciudad de Yecla puede formar parte del denominado turismo cultural. Actualmente dentro de los Itinerarios Culturales del Consejo de Europa - salvo por la excepción de la ruta del enoturismo, como ya apuntaba más arriba - no casamos en ninguno, esperamos que pronto se planteen la creación de nuevas rutas centradas en 'Arquitectura de la Edad Moderna' o 'Edificios en tiempos de los Reyes Católicos' para poder formar parte de ellos.

¿Podrían estos elementos patrimoniales establecer relaciones de identidad con la población actual de la ciudad y, por lo tanto, de respeto y usos adecuados del patrimonio? Para responder a esta pregunta podemos utilizar las palabras del escritor Luis Sepúlveda "la importancia de conocer el pasado para comprender el presente e imaginar el futuro". Si entendemos la identidad como "el conjunto de rasgos propios de un individuo o de una colectividad que los caracterizan frente a los demás", y el patrimonio como un recurso de desarrollo para la sociedad. Además, el uso del patrimonio como elemento de identidad supone una oportunidad para mejorar la consideración y el uso social del mismo, dando lugar a importantes mejoras en su conservación y gestión.

Así pues la complejidad del patrimonio de la ciudad del Yecla mediante una ruta cultural, apostando por su puesta en valor como instrumento de desarrollo del turismo cultual que permita aunar pasado y presente para que pueda ser incorporado como un activo económico más del municipio. 